\title{
PARQUES LINEARES DO TREMEMBÉ: O USO DE INFRAESTRUTURAS VERDES NA CRIAÇÃO DE UM SISTEMA DE ESPAÇOS LIVRES
}

\author{
LINEAR PARKS OF TREMEMBÉ: THE USE OF GREEN INFRASTRUCTURE \\ TO CREATE A SYSTEM OF FREE SPACES
}

Gerson Amaral Lima*

Paulo Renato Mesquita Pellegrino**

\section{RESUMO}

Este trabalho consiste na elaboração de uma proposta de intervenção paisagística numa porção da Subprefeitura Jaçanã/Tremembé no município de São Paulo. A região compõe a zona de amortecimento do Parque Estadual da Cantareira, e o adensamento construtivo do bairro constitui uma ameaça à preservação do meio ambiente local. $O$ projeto toma como diretriz o tratamento das águas urbanas, especialmente na requalificação dos fundos de vales, introduzindo novos conceitos de manejo das águas urbanas que se baseiam na ideia de Desenvolvimento de Baixo Impacto (Low Impact Development - LID). A proposta deste trabalho busca, também, estabelecer novas relações entre a cidade e os seus recursos naturais, tecendo novas costuras entre a floresta e a cidade.

Palavras-chave: Paisagem. Ambiente. Águas urbanas. Drenagem.

\section{ABSTRACT}

This work consists in developing a proposal for a landscape intervention in the area of the Subprefeitura Tremembé/Jaçanã, in São Paulo. The region constitutes the buffer zone of the Cantareira State Park and the densification of the neighborhood threatens the preservation of the local environment. The project takes as its guideline the treatment of urban waters, especially in requalification of river valleys, introducing new concepts of urban water management that are based on the idea of Low Impact Development (LID). The proposal also seeks to set up a new relation between the city and its natural resources, weaving a new relation between the forest and the city.

Keywords: Landscape. Environment. Urban waters. Drainage.

\footnotetext{
* Arquiteto e urbanista pela Universidade Federal do Ceará (UFC). Especialista em Paisagismo pela Universidade de Fortaleza (Unifor). Mestrando em Arquitetura e Urbanismo pela Faculdade de Arquitetura e Urbanismo da Universidade de São Paulo (FAUUSP). Avenida Antônio Sales, 2.132, ap. 104, Joaquim Távora, 60135-101, Ceará, Fortaleza, Brasil. gersonamaral.arq@gmail.com

** Arquiteto pela Pontifícia Universidade Católica de Campinas (PUC-Campinas). Mestre, doutor e pós-doutor pela Faculdade de Arquitetura e Urbanismo da Universidade de São Paulo (FAUUSP). Departamento de Projeto da FAUUSP. Rua do Lago, 876, Cidade Universitária, 05508-900, Caixa Postal 51623, São Paulo, SP, Brasil.

prmpelle@usp.br
} 


\section{INTRODUÇÃO}

Em 2014, os trabalhos acadêmicos da disciplina Sistema de Espaços Livre Públicos do curso de pós-graduação da Faculdade de Arquitetura e Urbanismo da Universidade de São Paulo (FAUUSP) focou no estudo sobre os espaços livres públicos urbanos e sua importância na construção coletiva do espaço das cidades brasileiras. A disciplina, ministrada pelos professores Eugênio Queiroga e Catharina Lima, tomou como área de estudo para as atividades do semestre a zona norte da capital paulista, especificamente o recorte da Subprefeitura de Jaçanã/Tremembé.

Os olhares voltaram-se para essa área em virtude de sua localização geográfica peculiar, ao compor parte da zona de amortecimento do Parque Estadual da Cantareira, uma das maiores florestas urbanas do mundo, e especialmente, por ser uma região que, nas últimas décadas, tem apresentado intensos conflitos entre as necessidades de preservação das áreas fronteiriças da floresta e o avanço da malha urbana e do adensamento construtivo impulsionado pelo mercado imobiliário.

Os estudos de aproximação com a realidade do bairro contaram com estudos da evolução histórica dessa região da cidade e palestras de pesquisadores e gestores da subprefeitura que elucidaram como se constituiu a atual dinâmica de crescimento urbano da área, seus problemas econômico-sociais, sanitários, ecológicos, de mobilidade. Os estudos foram incrementados, também, pela explanação das atuais intenções governamentais para intervenção no local, com projetos de grande impacto, como construção do rodoanel, previsão de passagem do trem Rio-São Paulo-Campinas, projetos de controle de enchentes e de parques lineares já previstos para os rios da região.

\section{DESAFIOS DO CRESCIMENTO URBANO BRASILEIRO}

O crescimento acelerado da população urbana ao longo do século XX, resultando em estruturas urbanas cada vez maiores e mais complexas, vem gerando novos desafios para o planejamento e a gestão de nossas cidades. Entre vários problemas decorrentes desse processo nas metrópoles brasileiras, figura como um dos mais preocupantes o de acesso à terra urbana em virtude da atual conjuntura econômica, que tem determinado as regras de produção do espaço da cidade. Essa prática exclui as camadas mais carentes da população, que não possuem condições econômicas de se incorporarem formalmente no mercado imobiliário, especialmente nas áreas mais bem infraestruturadas da cidade.

A cidade de São Paulo tem sofrido consequências desse processo especialmente a partir da década de 1940, quando ações como o Plano de Avenidas Prestes Maia promoveram a criação de um sistema de transporte público rodoviário que incrementou o mercado imobiliário nas regiões mais afastadas do centro. (HERLING, 2002). Atraída pelo menor preço da terra, o crescimento periférico da cidade é composto, majoritariamente, por uma população pobre que, com dificuldade de arcar com o custo das zonas mais bem estruturadas, busca alternativas em áreas menos favorecidas. Não raras vezes, 
essa população acaba por fixar-se em loteamentos irregulares, ocupações de terrenos públicos ou privados de áreas de proteção ambiental, margens de rios e mananciais.

A velocidade da expansão urbana informal, associada à fragilidade institucional dos municípios, enfraquece o papel do poder público enquanto agente planejador e disciplinador da produção de espaços urbanos, produzindo extensas áreas completamente carentes de saneamento básico, rede de transportes e equipamentos institucionais. Pelos mesmos motivos, o território da cidade vem eliminando gradativamente a quantidade de espaços verdes presentes no interior do perímetro urbano, notadamente espaços livres de uso público.

\section{A SUBPREFEITURA DE JAÇANÃ/TREMEMBÉ}

A Subprefeitura de Jaçanã/Tremembé localiza-se na região norte da cidade de São Paulo, limitando ao sul com as Subprefeituras de Santana/Tucuruvi e Vila Maria/Vila Guilherme; a leste com o município de Guarulhos; a oeste e norte com o município de Mairiporã. Possui área de 65,3 km² e sua população é de 291.867 mil habitantes. Da porção norte da subprefeitura, 27,67 km² compõem parte do Parque da Serra da Cantareira, onde se localizam os núcleos Águas Claras e Engordador.

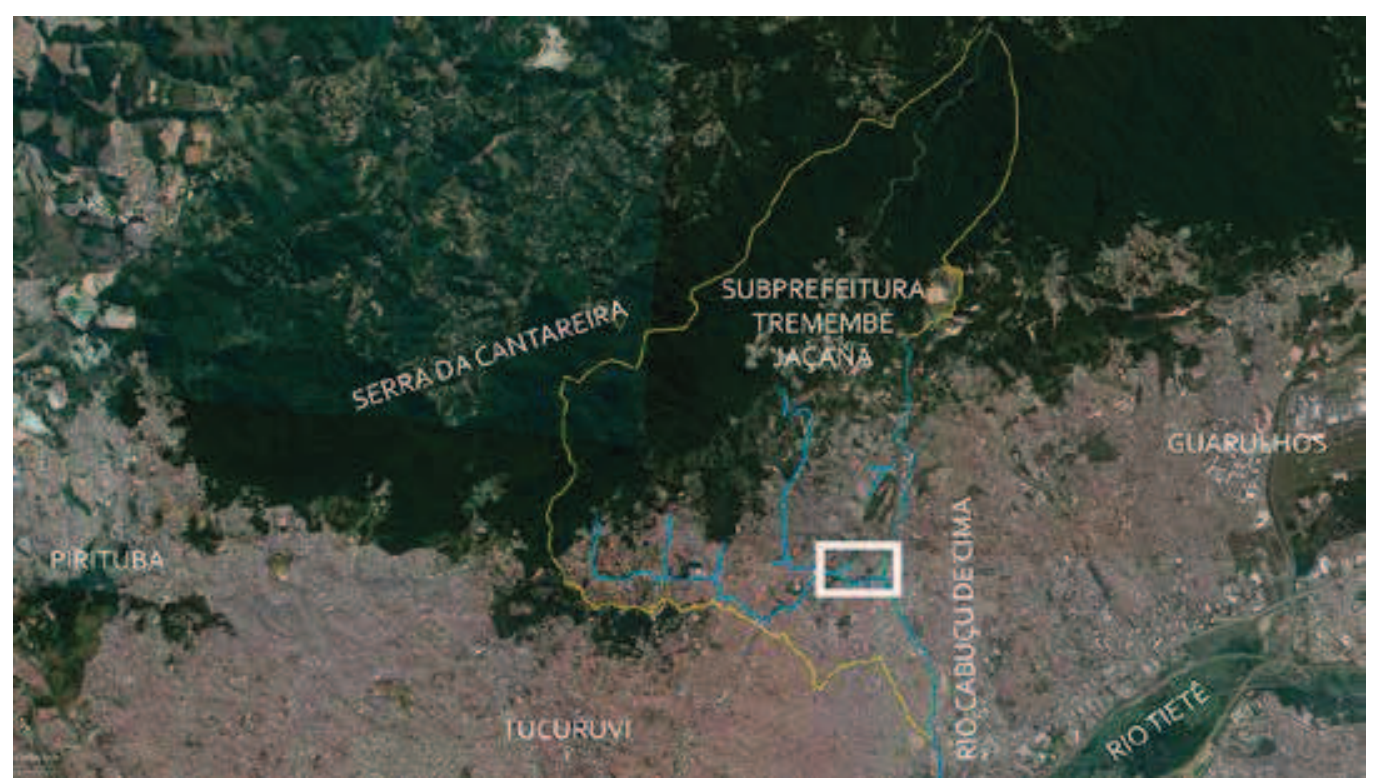

Figura 1 Área em estudo (retângulo branco) no contexto da Subprefeitura de Jaçanã/Tremembé e a serra da Cantareira.

Fonte: Elaborada por Gerson Amaral sobre base Google Earth. Disponível em: <https://www.google.com.br/maps/ place/Trememb\%C3\%A9,+S\%C3\%A3o+Paulo+-+SP/@-23.4536867,-46.6345541,19780m/data=!3m 1! 1 e3!4 $\mathrm{m} 2$ !3m1!1s0x94cef6f847876953:0x421ded09d34618c3>. Acesso em: 3 de jun. 2014

Até meados do século XX, a região era marcada pela existência de pequenas propriedades rurais que se dedicavam à agricultura familiar. Essas propriedades rurais compunham um cinturão verde que estabelecia transição entre a malha urbana da 
capital em expansão a sul e a reserva da serra da Cantareira, que tinha preservação assegurada pela função primordial de garantir o suprimento de água potável para a cidade. O crescimento acelerado da metrópole durante o século XX exigiu remodelações drásticas no sistema de abastecimento de água, que, em função do aumento da demanda, buscou a extensão das áreas de captação para outras bacias hidrográficas, localizadas ao norte da serra, para além dos limites do município, expandindo consideravelmente a sua capacidade. (HERLING, 2002).

Com a obsolescência do sistema de captação das águas da Cantareira, a floresta perdeu, gradativamente, sua importância enquanto manancial, ao mesmo tempo em que a expansão urbana pressionava cada vez mais as suas áreas limítrofes, convertendo as fazendas e pequenas propriedades rurais em bairros consolidados e eliminando, pouco a pouco, o cinturão verde rural que margeava a floresta.

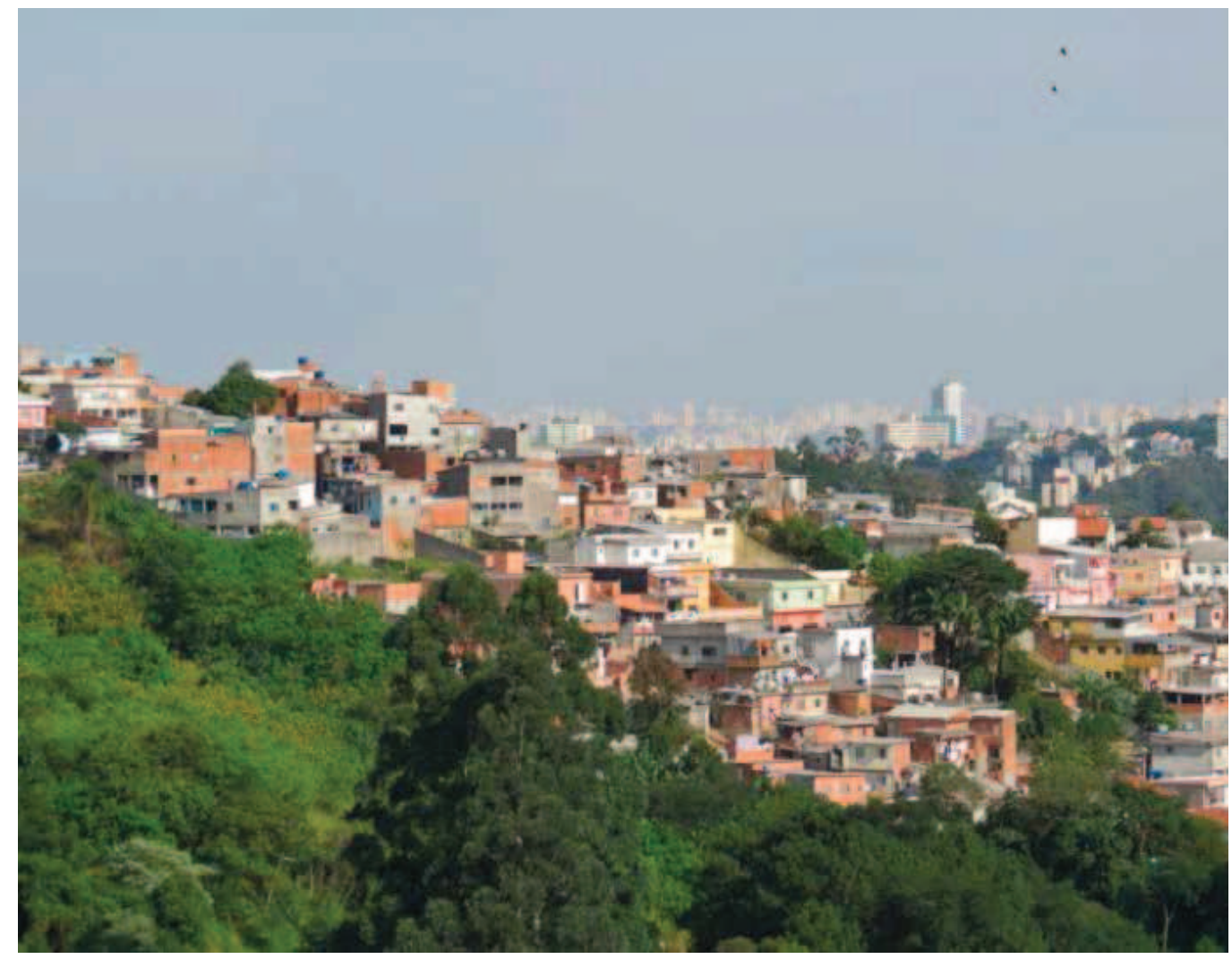

Figura 2 Ocupações irregulares avançam sobre área de floresta da Cantareira.

Foto: Gerson Amaral - 2014

Atualmente, os bairros componentes da Subprefeitura Jaçanã/Tremembé, à semeIhança de bairros periféricos da metrópole paulistana, são fortemente marcados pelo crescimento urbano acelerado, composto, basicamente, por população de baixa renda em busca de acesso a terras urbanas com preços mais acessíveis. Adicionalmente, verifica-se um conjunto considerável de ocupações irregulares, especialmente em zonas de proteção ambiental, muitas conformando áreas de risco (figura 2). 


\section{PROBLEMAS URBANÍSTICOS DA SUBPREFEITURA}

A área em pauta é resultado típico do padrão de desenvolvimento periférico da metrópole paulistana, refletindo todos os problemas encontrados em outras áreas desta.

Uma análise ampla e pormenorizada dos problemas urbanísticos da região demandaria volume considerável de dados e estudos - por isso, destacaremos como recurso didático apenas aspectos que possuam vínculo direto com a nossa abordagem, a qual foca como o desenvolvimento e a dinâmica do bairro conformaram, no seu desenho urbano, a relação com seus recursos naturais, especialmente hídricos, e estruturação dos espaços verdes públicos dos bairros. Será feita uma rápida análise de problemas relacionados ao relevo, à hidrografia e malha viária, a limites, barreiras, equipamentos institucionais, espaços verdes e áreas de ocupação de risco.

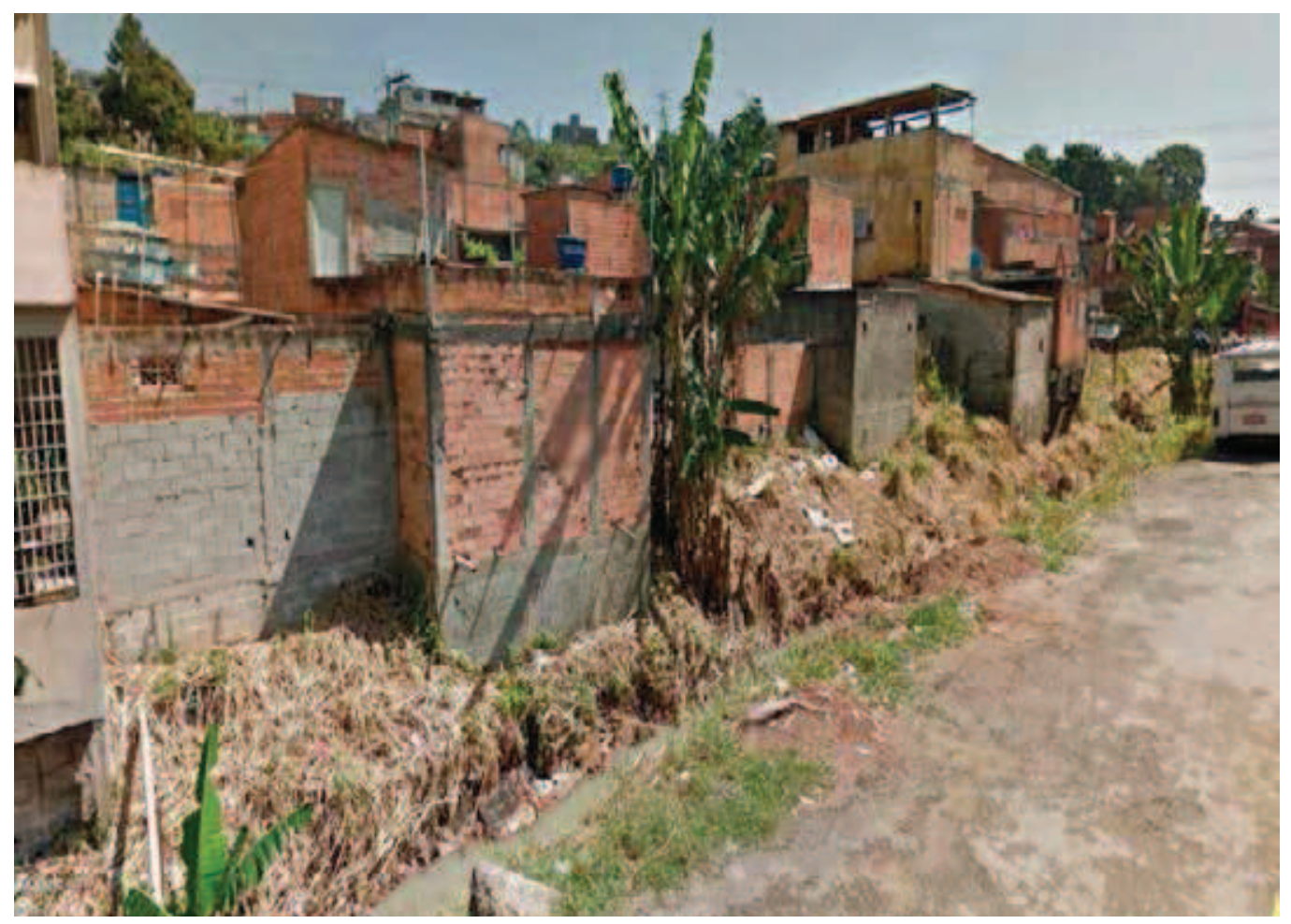

Figura 3 Ocupação e assoreamento do leito de riachos.

Fonte: Google Street View. Disponível em: https://www.google.com.br/maps/place/

Trememb\%C3\%A9,+S\%C3\%A3o+Paulo+-+SP/@-23.45094,-46.58095,3a,75y, 187.92h,76.26t/

data $=! 3 \mathrm{~m} 6 ! 1 \mathrm{e} 1 ! 3 \mathrm{~m} 4$ ! 1ssw-SHD_JQUWgbel_eyr1KA!2e0!7i13312!8i6656!4m2!3m1!1s0x94cef6f847876953:0x 421 ded

A mobilidade, em toda a área, é prejudicada em função de uma situação periférica da região em relação ao centro da cidade. A subprefeitura carece de uma centralidade de bairro com dimensão proporcional à sua dimensão urbana. Percebe-se que diversos bairros estabelecem conexões mais sólidas com as regiões centrais do que entre si. Basta uma análise rápida das linhas de ônibus do bairro para constatação desse fenômeno. Essa dificuldade é reforçada pela conformação viária que, condicionada por relevo 
fortemente acidentado, resulta num bairro marcado pela descontinuidade no traçado viário e carência de conexões entre diversos setores que o compõem.

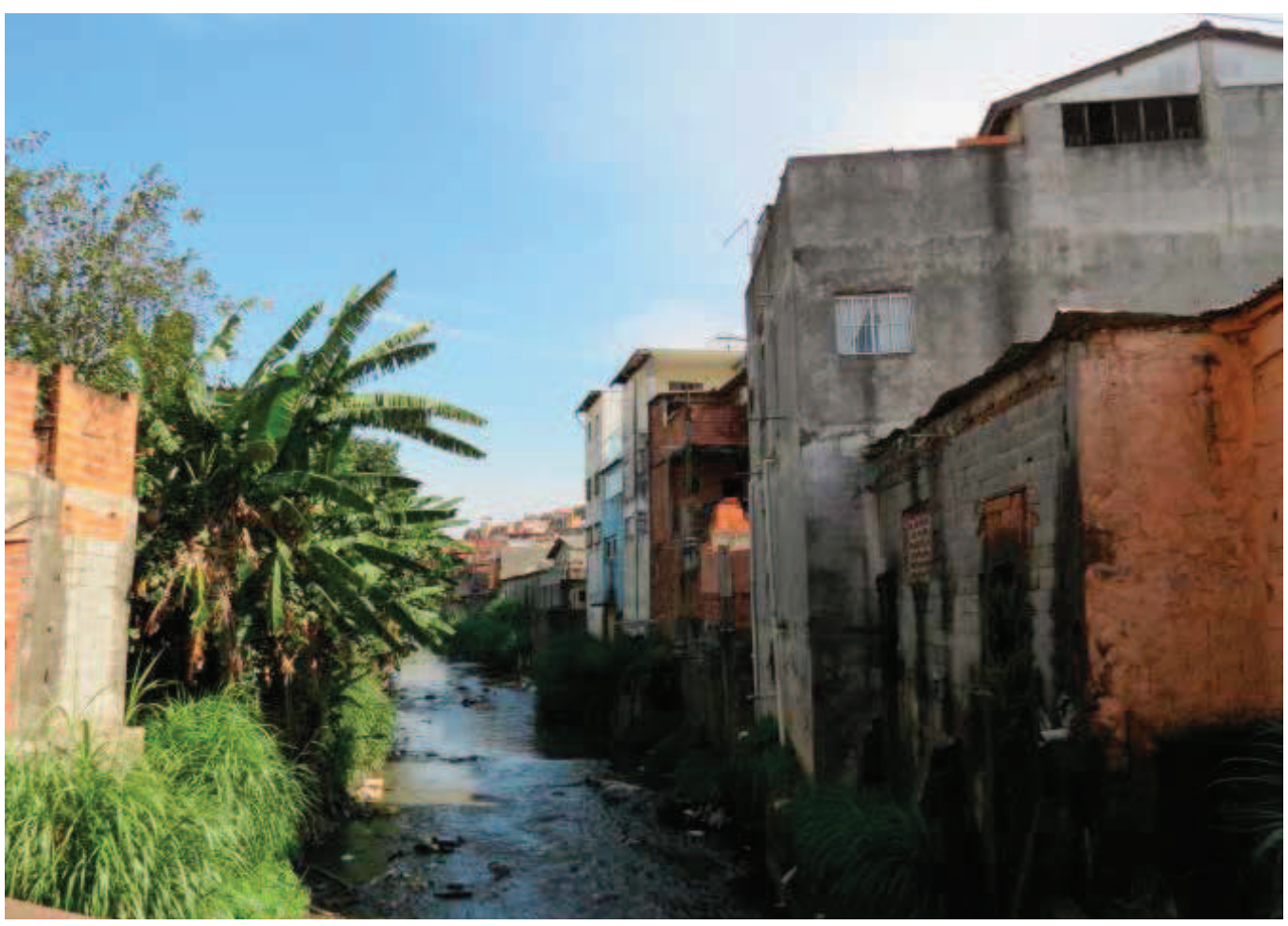

Figura 4 Ocupação das margens do rio Piqueri com lançamento de esgoto no corpo hídrico. Foto: Gerson Amaral - 2014

A mobilidade, em toda a área, é prejudicada em função de uma situação periférica da região em relação ao centro da cidade. A subprefeitura carece de uma centralidade de bairro com dimensão proporcional à sua dimensão urbana. Percebe-se que diversos bairros estabelecem conexões mais sólidas com as regiões centrais do que entre si. Basta uma análise rápida das linhas de ônibus do bairro para constatação desse fenômeno. Essa dificuldade é reforçada pela conformação viária que, condicionada por relevo fortemente acidentado, resulta num bairro marcado pela descontinuidade no traçado viário e carência de conexões entre diversos setores que o compõem.

Em função do relevo acidentado, as barreiras para a continuidade urbana são compostas por encostas de forte inclinação e pelos rios e riachos da região. Tais áreas constituem áreas com sérias restrições de ocupação por parte do setor formal da construção civil por constituírem Áreas de Preservação Permanente (APPs), zonas prioritárias para proteção de recursos naturais. A falta de políticas sistemáticas de proteção e qualificação dessas áreas acaba por deixá-las vulneráveis à sua ocupação informal - na maioria das vezes composta por população de baixíssima renda, pouca escolaridade e com construções de baixo padrão construtivo.

No caso dos terrenos com forte declividade, as ocupações informais impactam seriamente na estabilidade do solo pela retirada da vegetação, impermeabilização do 
solo e aceleração de processos erosivos. Por sua vez, as ocupações nos leitos dos rios impactam diretamente na vazão e na qualidade da água em virtude da impermeabilização intensiva do solo, do tamponamento de nascentes, riachos, aumento da velocidade de vazão, da polvição por lixo e do lançamento de esgoto doméstico in natura.

\section{JUSTIFICATIVA PARA A ESCOLHA DO RECORTE ESPACIAL DO ESTUDO}

A escolha da área de intervenção tomou como estratégia o tratamento das áreas próximas aos recursos hídricos da região. Áreas que, em face do crescimento urbano explosivo, tiveram características ecológicas seriamente alteradas e, por vezes, eliminadas enquanto componentes da paisagem dos bairros. Para além dos prejuízos ambientais, essas ocupações constituem sérios problemas urbanísticos, oriundos da péssima qualidade das construções, precariedade do traçado urbano, insalubridade e falta de infraestrutura básica.

A estruturação através das linhas de drenagem também se justifica por constatarmos que em suas margens se encontra a maior parte das ocupações de risco. São áreas de extrema fragilidade ambiental e social por estarem sujeitas a variações do volume de água dos córregos, sofrendo, frequentemente, efeitos de transbordamentos e enxurradas. Somadas a isso, as construções - de baixa qualidade - que caracterizam essas áreas carecem de infraestrutura sanitária adequada, o que resulta na prática de lançamento do esgoto doméstico no leito dos rios sem qualquer tratamento prévio. Daí se originam altos níveis de poluição das águas dos córregos pelo lançamento de lixo doméstico e pela polvição difusa.

Como foco de exercício projetual o recorte escolhido tomou como estratégia a escolha de um trecho da bacia do rio Tremembé, próximo ao ponto onde deságua no rio Cabuçu de Cima, junto à rodovia Régis Bittencourt. A partir da foz, a área de intervenção contempla o curso do rio Tremembé e os territórios lindeiros, seguindo a montante até sua confluência com o riacho Piqueri. Deste ponto, a área segue pelo curso do rio Piqueri até seu cruzamento com a avenida Antonelo da Messina. Somamse a essa unidade de intervenção os pequenos riachos e cursos d'água afluentes do Tremembé e Piqueri - como o lgarapé Primavera, que deságua no rio Piqueri - e suas áreas de influência imediatas.

A área delimitada por esse recorte apresenta uma complexidade de elementos que permite a exploração de soluções diversas em função das diferentes características nos seguintes aspectos:

- hidrografia: os cursos hídricos da área apresentam uma pluralidade de configurações, como áreas próximas às nascentes, trechos onde temos a confluência de dois importantes cursos d'água (Piqueri e Tremembé) e trechos do rio Tremembé com seu maior volume de vazão pela proximidade com a sua foz; essas três situações exemplificam, claramente, configurações típicas de um rio, 
desde sua nascente até sua foz, considerando configurações mais comuns dos rios da região;

- relevo: as configurações de relevo também são diversificadas no local: ao longo das margens dos cursos d'água, encontram-se exemplos de pequenas planícies inundáveis, encostas vegetadas com forte inclinação e vales estreitos; assim como nos recursos hídricos, essas configurações de relevo são próprias de grande parte da área norte da cidade de São Paulo;

- urbanismo: a área apresenta concentração de equipamentos institucionais - delegacia, hospital, escolas primárias, escolas secundárias, escola técnica, Fábrica de Cultura e o CEU (Centro de Artes e Esportes Unificados) Jaçanã e é cortada pelas vias estruturantes do bairro; a implantação do CEU neste ponto foi providencial, por ser a área que mais possui vocação para configurar-se como forte centralidade de bairro.

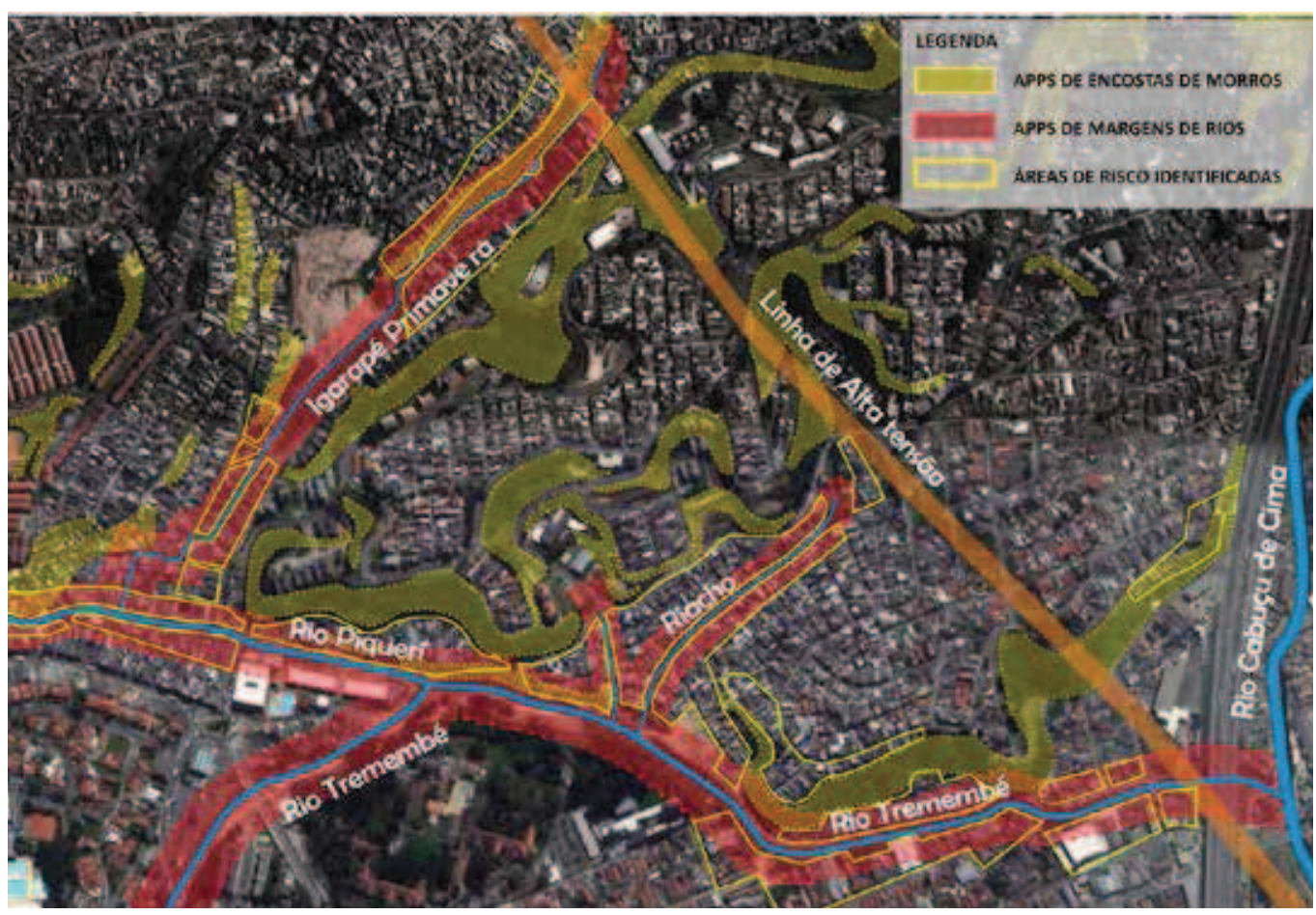

Figura 5 Área de intervenção escolhida. Manchas vermelhas indicam APPs nas margens dos rios. Manchas em amarelo indicam APPs nas encostas de morros. Poligonais em amarelo indicam áreas de ocupação irregular, precárias ou de remoção necessária para implantação da proposta de requalificação.

Fonte: Elaborada por Gerson Amaral sobre base Google Earth. Disponível em: < https://www.google.com.br/ maps/place/Trememb\%C3\%A9,+S\%C3\%A3o+Paulo+-+SP/@-23.4554394,-46.5813654,1357m/data=!3m1!1 e3!4m2!3m1!1s0x94cef6f847876953:0x421ded09d34618c3>. Acesso em: 3 jun. 2014.

Localizada à margem dos trechos urbanos mais bem estruturados, a área do nosso recorte é fortemente marcada por ocupações irregulares que ocupam terrenos em encostas íngremes, nas margens de riachos ou até cortados por nascentes e corpos d'água 
que, em alguns trechos, foram tamponados. Essas situações estão em desconformidade com as leis ambientais e constituem, em boa parte, áreas de risco.

\section{ABORDAGEM CONCEITUAL - O ESPAÇO PÚBLICO E A ECOLOGIA DA PAISAGEM}

Enquanto componente fundamental da paisagem urbana, o espaço livre público pode ser entendido como resultado das interações humanas com os processos naturais através do tempo, configurando-se, também, como registro do que se passou em uma cultura em termos de sua relação com a natureza. (SPIRN, 1995). Para Metzger (1999), a paisagem é uma unidade heterogênea, composta por unidades interativas, como ecossistemas, unidades de vegetação, unidades de uso e ocupação do solo. Pensar na paisagem urbana, hoje, significa aceitar, de maneira crítica e coerente, as inúmeras transformações que sofreu, analisando benefícios e prejuízos que sua configuração atual vem trazendo para a população e o meio ambiente.

São inúmeros os alertas, no âmbito mundial, sobre consequências negativas de ações humanas insensatas na paisagem, que geram problemas como: aquecimento global, alterações na renovação natural e polvição de recursos hídricos, redução e extinção de espécies animais e vegetais, crescimento populacional desordenado (e suas implicações), insustentabilidade do sistema econômico vigente.

Como resposta a esses alertas, o campo da arquitetura e urbanismo tem cada vez mais aprofundado suas investigações sobre soluções projetuais sustentáveis, tendo como objetivo o conforto ambiental, a conservação da energia e a utilização apropriada dos materiais e componentes das estruturas construídas, verificando seus efeitos através da análise do desempenho ambiental. Os espaços assim projetados são adequados ao lugar e concebidos segundo preceitos bioclimáticos.

A ecologia passou a desempenhar importante papel no desenvolvimento dos municípios, incluindo seus espaços urbanos e rurais. Esse processo obriga as mais diversas disciplinas a repensar suas técnicas e formas de intervenção no território. (MAGALHÃES, 2001).

O processo de urbanização, planejado ou não, acarreta mudanças significativas nas características do sítio. $\bigcirc$ processo de desmatamento com retirada da vegetação original, as mudanças das configurações topográficas para implantação de vias e edificações, a impermeabilização do solo e a implantação de sistemas convencionais de drenagem modificam consideravelmente os processos hidrológicos incidentes nas bacias hidrográficas, onde se constata o aumento da velocidade de escoamento das águas. Esta é a causa do agravamento das inundações e da poluição difusa das águas de córregos e rios.

A visão ecossistêmica da paisagem urbana tem encarado problemas decorrentes de alterações promovidas no ciclo hidrológico. Nessa perspectiva, enquanto ações projetuais, os espaços livres públicos passam a ser incorporados a estratégias de intervenções paisagísticas que, além de mero embelezamento urbano, passam a desempe- 
nhar funções infraestruturais relacionadas ao manejo das águas urbanas e ao conforto ambiental, à biodiversidade, a alternativas de circulação, acessibilidade e imagem local. (PELLEGRINO; CORMIER, 2006).

Conforme destaca Queiroga (2012), "[...] a contribuição ambiental dos espaços permeáveis e vegetados de uma cidade, por exemplo, se constitui importante serviço ambiental urbano, mesmo que não estejam conectados fisicamente". Sob uma abordagem ecológica, podemos considerar que Olmstead foi o precursor no tratamento dos espaços verdes de uma cidade enquanto sistema. Em seu projeto de requalificação urbana, toma como princípio norteador o controle no fluxo da drenagem de um trecho da cidade de Boston. (SPIRN, 1995). Esse exemplo, considerado referência no tratamento de águas urbanas associado à requalificação paisagística, elucida a importância da abordagem sistêmica nas ações de requalificação dos espaços urbanos, tomando a drenagem como eixo estruturador. A drenagem urbana, ao contrário de outras utilidades públicas - como água, esgoto, eletricidade, gás -, é intrinsecamente ligada ao processo de urbanização. É sua consequência direta. Não pode ser dissociada e não é um problema somente hidráulico, como normalmente tratada, mas sim um problema urbano que demanda visão ampla sobre o processo de urbanização do qual faz parte. (CANHOLI, 2005).

\section{PROJETO DE REQUALIFICAÇÃO}

O objetivo do projeto em pauta é reverter o dramático quadro do bairro, marcado por forte adensamento e crescimento da malha urbana com impacto direto sobre a floresta e seu ecossistema. Pela importância metropolitana dessa floresta, é desejável a contenção e até a reversão desse quadro de adensamento, procurando novas relações da floresta com o meio urbano que dela se aproxima.

Na tentativa de diluir o contraste entre espaço urbano e área de floresta, a estratégia de intervenção tenta tecer novas costuras entre a floresta e a cidade. A via encontrada para dar início a criação dessa nova postura consistiu na estruturação de um sistema de espaços verdes associado às linhas de drenagem. Segundo Herling (2002), a adoção da bacia hidrográfica como unidade de planejamento e gestão dos recursos hídricos, presente no arcabouço legislativo e institucional e nas propostas técnicas delineadas ao longo dos anos 1990 em São Paulo, aponta para a recuperação da visão sistêmica na exploração de recursos naturais na cidade.

A primeira vantagem dessa abordagem é a erradicação das áreas de risco por serem áreas vulneráveis a cheias periódicas, à exposição ao lixo, a odores e vetores de doenças; a segunda consiste na recuperação dos córregos e rios enquanto recursos naturais, no aumento da área permeável do bairro e na proteção de suas nascentes; a terceira vantagem da estratégia consiste no estabelecimento de pontes ecológicas que conectem diversos espaços verdes do bairro, associadas a linhas de água que, se implantadas sistematicamente, em futuro próximo estabelecerão cinturões ecológicos intra e interbairros, favorecendo trocas gênicas entre diversos fragmentos de matas ainda existentes. 

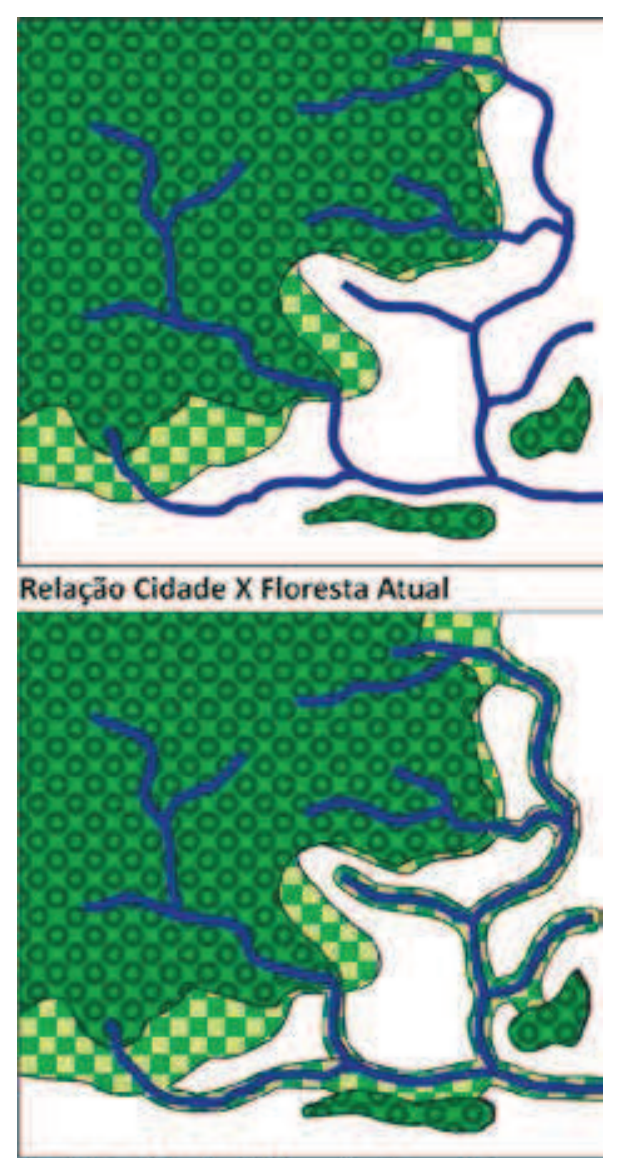

Relação Cidade X Floresta Proposta

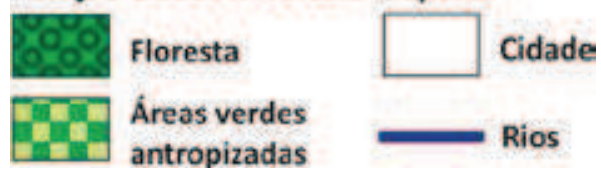

Figura 6 Nova relação cidade x floresta.

Fonte: Elaborada por Gerson Amaral - 2014

Trata-se de uma estratégia que permite conexão ecológica entre as nascentes localizadas, majoritariamente, na floresta da Cantareira - com as regiões mais baixas dos rios, conformando através desses elementos uma extensão do sistema ecológico da serra que, assim, desce seus contrafortes e atinge o interior da malha urbana criando tentáculos da floresta que, pouco a pouco, penetram na paisagem da cidade.

Segundo Queiroga (2012), o que confere natureza sistêmica ao conjunto de espaços livres são suas relações concretas, a dinâmica de suas interações, sendo que a questão ambiental não pode ser concebida como um sistema de espaços livres individualizados, mas sim como integrante de um sistema maior, que "[...] como um sistema aberto, o sistema de espaços livres urbano se relaciona ao sistema de espaços livres regional, e assim sucessivamente, participando de um sistema de sistemas, que se redefinem reciprocamente." (QUEIROGA, p. 284). Tal é o objetivo deste trabalho: que o sistema de espaços livres do bairro seja componente do sistema de espaços livres da subprefeitura, que, por sua vez, é componente do sistema ecológico da floresta da Cantareira - este sendo componente de um sistema maior em escala regional. 
O diferencial buscado nessa proposta, ao intervir nas margens de rios e na requalificação dos cursos d'água, diz respeito ao conceito que se contrapõe ao padrão atual de canalização de córregos, retificação de leitos e criação de piscinões para contenção de cheias. Sabe-se, por experiência, que o aumento da vazão de escoamento é um dos principais fatores que contribuem para cheias e alagamentos recorrentes na região. Assim como as soluções tradicionais adotadas para o combate desses alagamentos, os piscinões também já se demonstraram ineficazes, em virtude de problemas inerentes ao funcionamento e à manutenção, de prejuízos urbanos que constituem nos locais onde estão implantados - sendo espaços que não dialogam com o espaço ao redor, reduzindo-se a imensos vazios no interior da malha da cidade sem qualquer relação com o cotidiano ao seu redor.

A manutenção dos piscinões depende unicamente da iniciativa do poder público, que, na cidade de São Paulo, tem se demonstrado ineficiente. Dadas as condições de polvição dos rios da capital paulistana, as consequências dessa falta de manutenção são preocupantes. O acúmulo de lixo e o gradativo assoreamento dos piscinões reduzem significativamente sua eficiência para controle de cheias e, ao reterem esgotos domésticos in natura e polvição difusa, passam a funcionar como decantadores primários de estações de tratamento de esgotos no meio da cidade'.

Em contraposição a esse modelo em voga, propõe-se a adoção de novas tecnologias, de cunho mais sustentável, que busquem associar as estratégias de controle de cheia e vazão a melhor qualidade do desenho urbano, propondo novas relações do cidadão com o espaço urbano em que habita, assim como uma nova relação com os recursos hídricos que permeiam o bairro. $O$ projeto de manejo das águas se baseia no conceito de Desenvolvimento de Baixo Impacto (Low Impact Development - LID) - uma abordagem ecológica de gestão das águas pluviais na fonte (UACDC, 2010).

Essa estratégia busca diluir as soluções de controle de cheias ao longo de todo o curso hídrico, e não apenas em pontos específicos, o que faz com que seja uma estratégia sistemática de intervenção, que deve considerar para tratamento todo o rio, desde sua nascente até sua foz, em diversas escalas. Para tanto, um dos objetivos do projeto consiste no aumento das áreas permeáveis dentro da malha urbana, permitindo a recarga de aquíferos e a diminuição do escoamento superficial, ao mesmo tempo em que ajuda a estabilizar a vazão dos riachos.

A proposta fundamenta-se na retenção das águas superficiais através do uso de tipologias de projetos paisagísticos de alto desempenho:

1. canteiros pluviais: depressões topográficas que recebem a água do escoamento pluvial, proveniente de áreas impermeabilizadas, e desempenham funções de infiltração, transbordamento e evapotranspiração, além de tratarem a polvição difusa a partir de mecanismos naturais de plantas e microrganismos associados (fitorremediação). (CORMIER; PELLEGRINO, 2008);

Mais informações sobre piscinões em Armelin (2011). 
2. lagoas pluviais, wetlands ou alagados construídos: recebem o escoamento superficial dos sistemas de drenagem - natural ou convencional; retêm parte da água das chuvas entre os eventos de precipitação (CORMIER; PELLEGRINO, 2008); tratam a polvição e criam habitat para a fauna e flora silvestre (EPA, 2004); as espécies de plantas aquáticas (macrófitas) e suas complexas interações com os microrganismos associados agem na retenção, degradação e transformação de diversos tipos de polventes orgânicos, patogênicos e inorgânicos a partir de mecanismos de fitorremediação. (SHUTES, 2001);

3. floating rafts: ilhas flutuantes construídas; podem estar associadas aos wetlands, fixados nas margens dos corpos hídricos ou localizados mais centralmente, como ilhas ou arquipélagos; são estruturas vegetadas que trabalham a rizofiltração (filtragem pelas raízes das plantas) aplicada in situ. (BIOMATRIX WATER, 2012).

Todas as soluções adotadas focam na contenção das águas principalmente nas primeiras chuvas, para a retenção da polvição difusa. Quanto ao retardamento do escoamento são propostas, também, intervenções nas próprias linhas de drenagem, seja pelo aumento da rugosidade do canal através de rochas, elementos construídos, vegetação e desenho sinuoso do leito, seja através do barramento sucessivo em diversas escalas, criando pequenos lagos ao longo de todo o seu curso.

Sobre as estratégias de contenção das vazões, Canholi $(2005$, p. 16) afirma:

[...] os conceitos 'inovadores' mais adotados para a readequação ou o aumento da eficiência hidráulica dos sistemas de drenagem têm por objetivo promover o retardamento dos escoamentos, de forma a aumentar os tempos de concentração e reduzir as vazões máximas; amortecer os picos e reduzir os volumes de enchentes por meio da retenção em reservatórios; e conter, tanto quanto possível, o run-off no local da precipitação, pela melhoria das condições de infiltração, ou ainda em tanques de contenção.

Esses conceitos "inovadores" apontados por Canholi são responsáveis por grandes avanços nos projetos de drenagem urbana em São Paulo, inserindo novos paradigmas e fazendo repensar a lógica de tratamento das águas urbanas. São as bases dos princípios adotados em nossa proposta, contudo, os conceitos adotados por Canholi ainda desconsideram os impactos das infraestruturas de retenção das águas pluviais na paisagem da cidade, além de não oferecerem soluções para a melhoria da qualidade das águas. A introdução de estratégias LID contribui para a solução dessas carências.

Naturalmente, essas estratégias, ao respeitarem os espaços exigidos pela dinâmica ecológica, demandam a preservação de margens e encostas. A solução urbanística adotada pelo projeto considera a remoção de todas as ocupações irregulares nas margens dos córregos e encostas com risco de deslizamento. $\bigcirc$ redesenho das margens dos cursos d'água prevê a criação de espaços livres de inundações nos quais serão reassentadas as famílias, optando pela verticalização como solução arquitetônica para atendimento de toda a população relocada. 
Coleta de resíduos sólidos e um programa de saneamento do bairro garantiriam o destino correto dos efluentes e do lixo, principais fontes das cargas polvidoras atualmente lançadas nos rios. Ruas, ciclovias, passeios, calçadões, passarelas, pontes, escadas e elevadores, entre outras infraestruturas, reconfigurariam espaços livres, tecendo novas conexões no bairro - pela transposição de barreiras naturais, como encostas e riachos -, nele ressignificando-os ao reinseri-los no cotidiano como elementos positivos da paisagem local.

A recuperação ambiental dos córregos inclui a reconfiguração das margens permeáveis e taludadas, permitindo o acesso de animais terrestres ao corpo hídrico. A vegetação aquática e a ripária, que será implantada nos canteiros e lagoas pluviais, também serão implantadas ao longo de todos os riachos, contribuindo para a retenção da polvição. O leito de drenagem será consolidado enquanto corredor ecológico, criando habitats para diversas espécies animais, como insetos, anfíbios, répteis, aves e mamíferos.

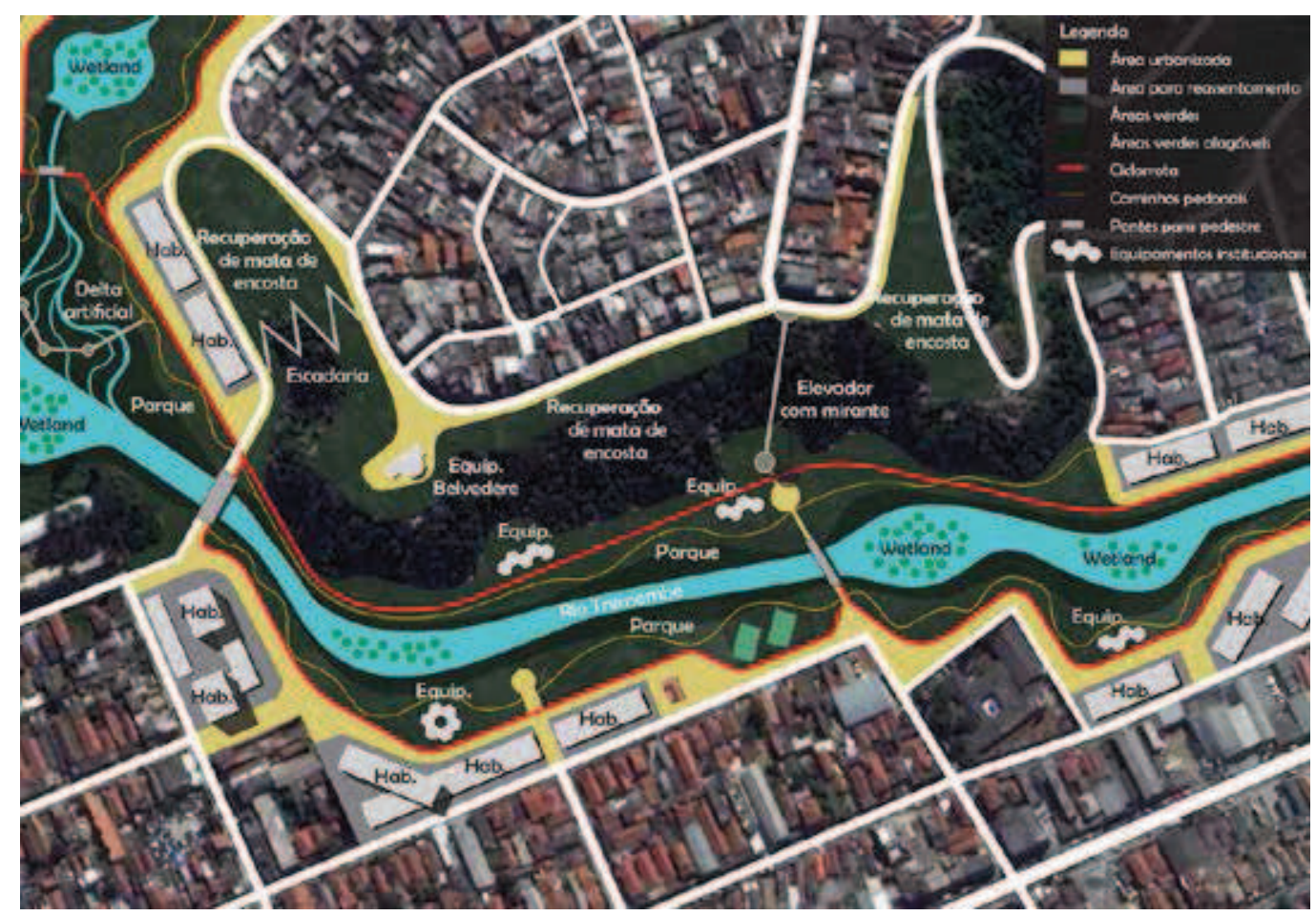

Figura 7 Intervenção proposta para trecho do rio Tremembé. $\bigcirc$ reassentamento das famílias removidas foi planejado para conjuntos verticalizados integrados à malha urbana e ao parque linear. A recuperação ambiental de encostas e margens de rios soma-se ao conjunto de equipamentos e à infraestrutura viária (veículos motorizados, não motorizados e pedestres). Mirante com elevador constitui marco visual na paisagem.

Fonte: Planta elaborada por Gerson Amaral sobre base Google Maps.

Disponível em: <https://www.google.com.br/maps/place/Trememb\%C3\%A9,+S\%C3\%A3o+Paulo+-+SP/@23.4582622,-46.5767004,479m/data =!3m1!1e3!4m2!3m1!1s0x94cef6f847876953:0x421 ded09d34618c3>. Acesso em: 3 jun. 2014 


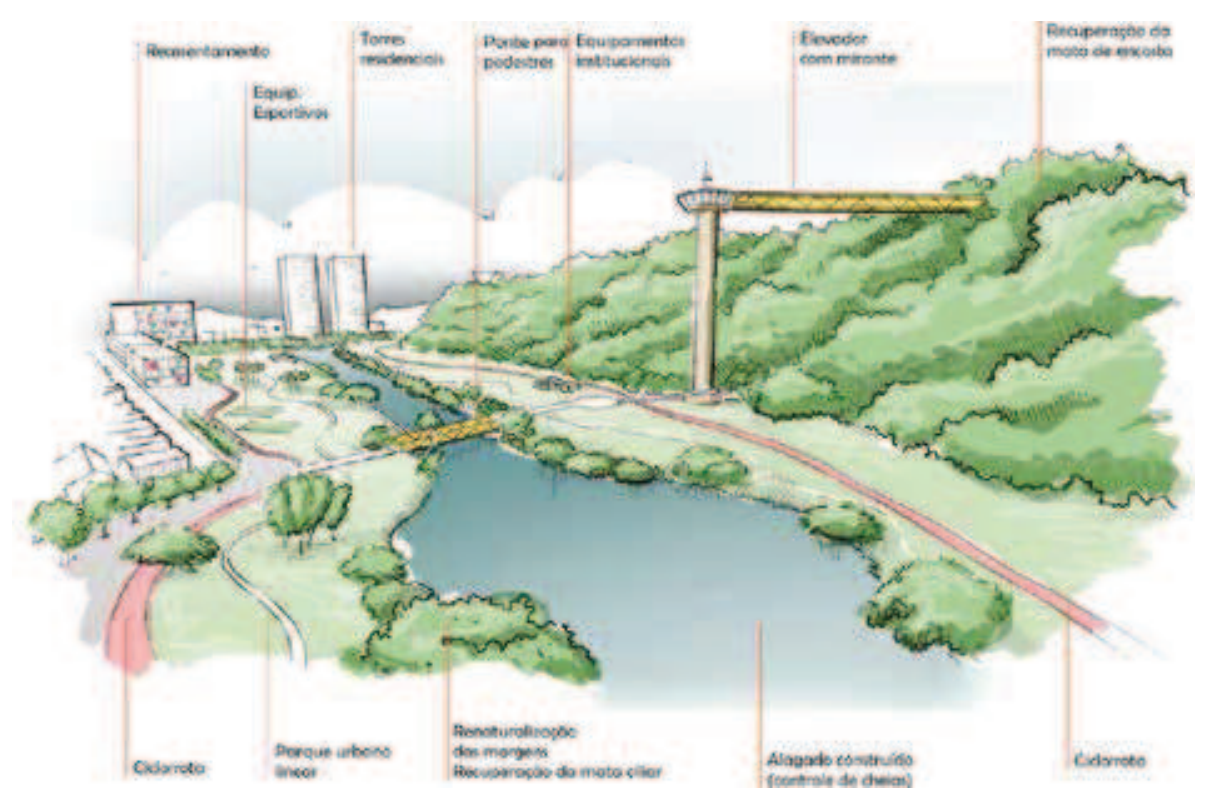

Figura 8 Perspectiva do trecho com a proposta de requalificação das margens de rios e encostas, criação de pontes, passarelas e mirantes com elevadores/escadas para novas conexões urbanas entre trechos de malha urbana hoje desconectados pelos acidentes geográficos. Um parque urbano linear se forma - não apenas como espaço livre de lazer, mas como elemento integrador das diferentes áreas do bairro, estabelecendo-se como centralidade linear.

Fonte: Elaborada por Gerson Amaral - 2014

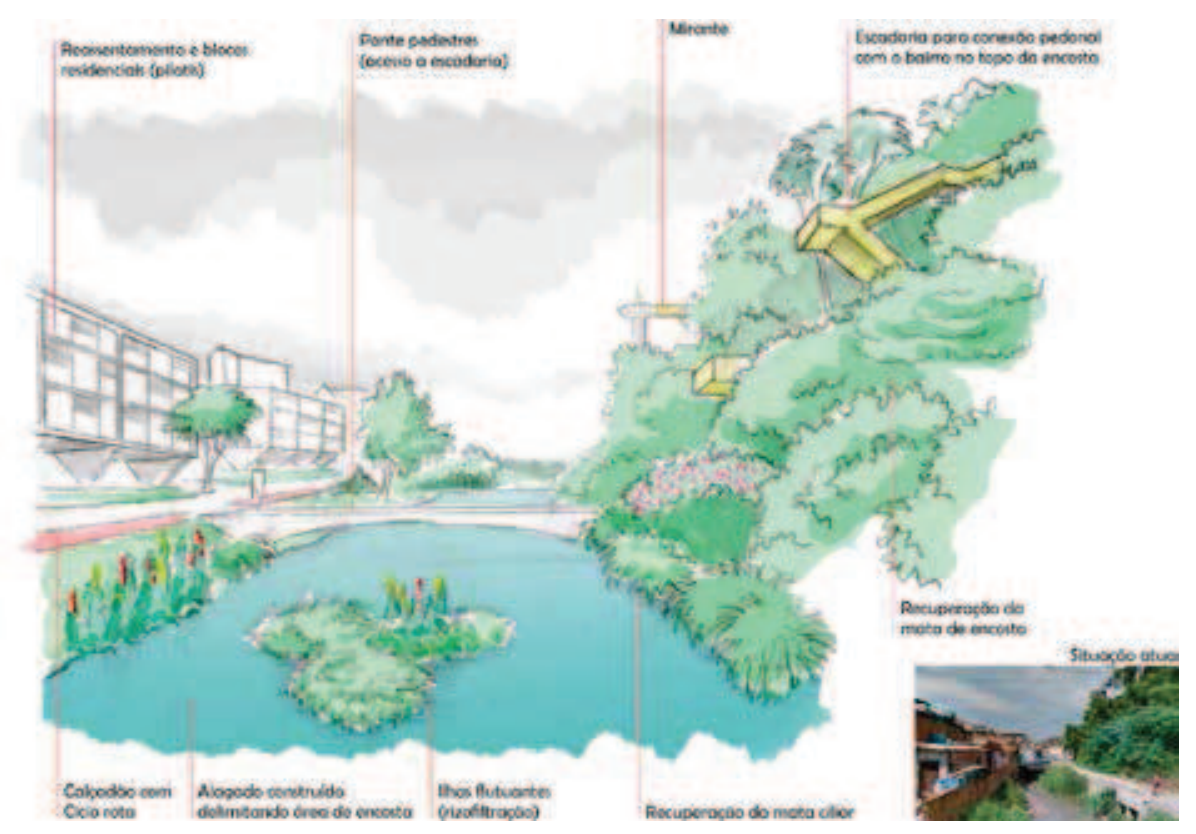

Figura 9 Proposta para o riacho Igarapé Primavera. À esquerda, blocos verticalizados para o reassentamento das famílias removidas em local próximo ao de origem. A criação de ponte sobre o rio garante acesso à encosta, que receberá escada e elevador para facilitar a transposição desse acidente geográfico. $O$ elevador apropria-se do potencial cênico que oferece através da criação de um mirante em seu topo. A encosta vegetada se insere na paisagem ao ser explorada em sua extensão vertical, integrando-se ao parque urbano linear criado. Fonte: Elaborada por Gerson Amaral - 2014 


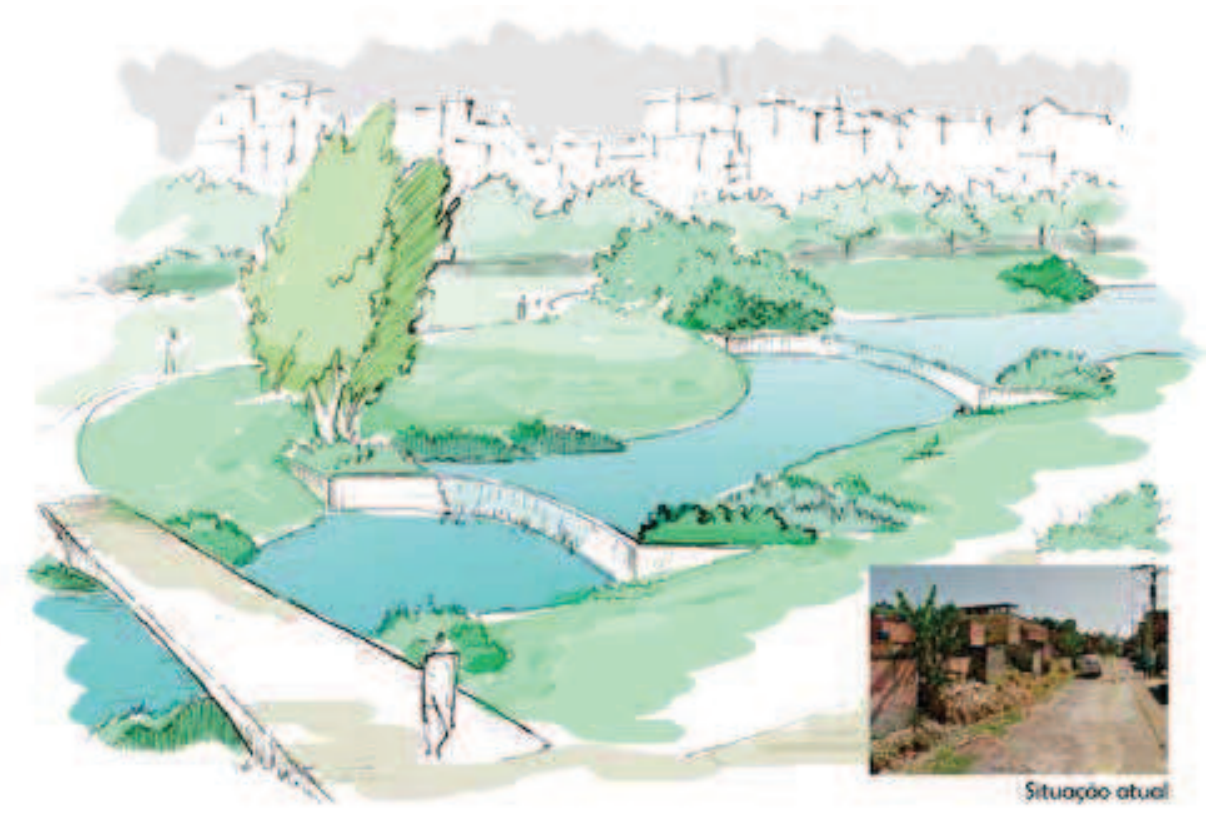

Figura 10 A retenção das águas das chuvas inclui o barramento de córregos para controle de vazão e criação de lagos, ampliando a presença do riacho na paisagem do bairro. O represamento sucessivo reduz a velocidade de escoamento, promove a decantação de sedimentos e ajuda na oxigenação da água, reduzindo o mau cheiro e facilitando a purificação através da biodegradação de polventes. O plantio de espécies aquáticas e vegetação ripária contribui para a retenção de polventes e abrigo para fauna.

Fonte: Elaborada por Gerson Amaral - 2014

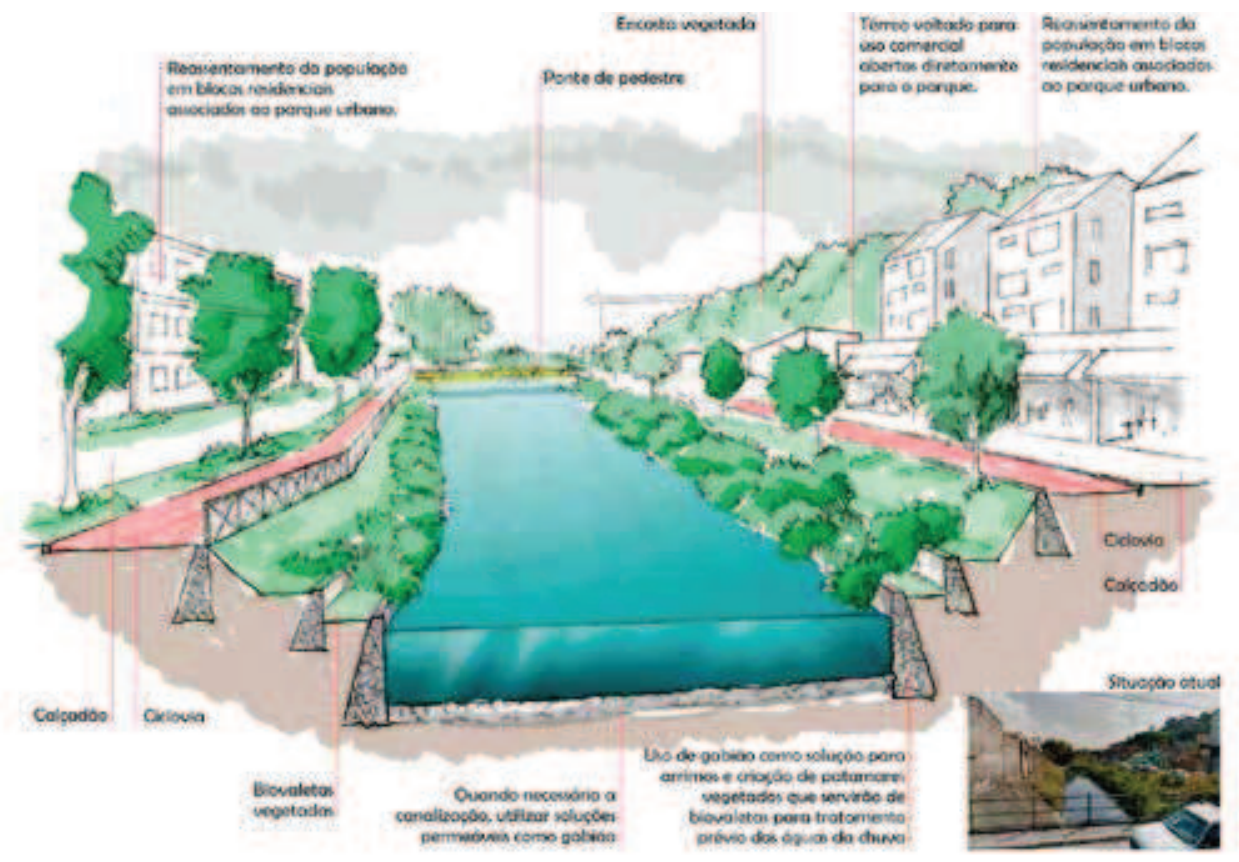

Figura $11 \mathrm{Em}$ trechos com menor disponibilidade de áreas, soluções de engenharia, como contenções em gabião, permitem o escalonamento das margens para promoção do reestabelecimento da vegetação ripária em biovaletas, liberando as áreas mais altas para instalação de passeios e ciclovias. Uso de jardins de chuva e pavimentação permeável contribuem para controle de cheias, melhoria da qualidade da água e enriquecimento da fauna e flora locais.

Fonte: Elaborada por Gerson Amaral - 2014 


\section{CONCLUSÃO}

Por mais que o homem tenha estabelecido uma dicotomia entre a natureza virgem e o produto do trabalho humano, não é possível mais desconsiderar que essas duas definições estão integradas a um conjunto de processos comuns, condicionados, igualmente, ao meio e aos processos naturais. A cidade, enquanto uma das maiores intervenções do ser humano sobre a terra, não está dissociada dos processos naturais que incidem sobre sua base física. $\bigcirc$ reconhecimento desses processos e sua incorporação ao cotidiano citadino cada vez se demonstram mais eficientes do que ações tradicionais de negação e controle dos processos naturais.

As intervenções humanas promovem sérias alterações na estrutura do ambiente natural. É preciso estar atento ao fato de que, quando ocorrem alterações suficientemente fortes para alterar sua estrutura, mudam-se sua organização e suas características (QUEIROGA, 2012), exigindo que tenhamos uma compreensão clara das demandas advindas dessa nova organização. Segundo Herling (2002, p. 62):

[...] a integração entre elementos naturais e elementos componentes dos sistemas de infraestrutura deve estar presente e visível na paisagem da cidade, evidenciando didaticamente a relação que se estabelece na apropriação e transformação dos recursos naturais para a produção dos sistemas de infraestrutura.

A paisagem, dessa forma, pode ser grande aliada para a sensibilização de agentes sociais sobre a importância da presença de elementos e sistemas naturais nos meios mais alterados pelo processo social. (QUEIROGA, 2012). Como afirma Santos (2006):

[...] a ordem espacial assim resultante é, também, intencional. Frutos da ciência e da tecnologia, esses objetos técnicos buscam a exatidão funcional, aspirando, desse modo, a uma perfeição maior que a da própria natureza. É desse modo que eles são mais eficazes que os objetos naturais e constituem as bases materiais para as ações mais representativas do período.

Por essas razões, a proposta em pauta busca estar atenta às indagações e posturas que hoje permeiam não só o campo do urbanismo, da infraestrutura ou da paisagem, mas de toda a forma de encarar nossa relação com o mundo onde vivemos. As soluções propostas para a requalificação de áreas do Tremembé/Jaçanã buscam estabelecer novas formas de estruturação da paisagem considerando as novas configurações espaciais do lugar. 


\section{REFERÊNCIAS BIBLIOGRÁFICAS}

ARMELIN, Liliane Frosini. Estudo do comportamento dos resíduos sólidos veiculados pelos rios urbanos junto aos vertedores de entrada de reservatórios de controle de cheias. 2011. 140 f. Tese (Doutorado em Engenharia Hidráulica) - Escola Politécnica da Universidade de São Paulo, São Paulo, 2011.

BIOMATRIX WATER. River restoration. 2012. Disponível em: <http://www.biomatrixwater.com/river-restoration/>. Acesso em: 28 de maio de 2014.

CANHOLI, Aluísio Pardo. Drenagem urbana e controle de enchentes. São Paulo: Oficina de Textos, 2005. 302 p.

CORMIER, Nathaniel S.; PELLEGRINO, Paulo Renato Mesquita. Infraestrutura verde: uma estratégia paisagística para a água urbana. Paisagem e Ambiente: ensaios. São Paulo: FAUUSP, n. 25, 2008, p. 127-142.

HERLING, Tereza. A floresta em São Paulo, a cidade na Cantareira: fronteiras em transformação. 2002. Tese (Doutorado em Arquitetura e Urbanismo) - Faculdade de Arquitetura e Urbanismo da Universidade de São Paulo, São Paulo. 2002

MAGALHÃES, Manuela Raposo. A arquitetura paisagista. Lisboa: Editorial Estampa, 2001. 525 p.

METZGER, Jean Paul. Estrutura da paisagem e fragmentação: análise bibliográfica. Anais da Academia Brasileira de Ciências, 71, 1999, p. 445-462.

PELLEGRINO, Paulo Renato Mesquita et al. A paisagem da borda: uma estratégia para a condução das águas, da biodiversidade e das pessoas. In: COSTA, Lúcia Maria Sá Antunes (Org.). Rios e paisagem urbana em cidades brasileiras. Rio de Janeiro: Viana \& Mosley Editora/Editora PROURB, 2006. pg. 57-76. ISBN: 85-88721-38-4.

; CORMIER, Nathaniel S. A regenerative ecological approach to stormwater in the city (.ppt). In: Palestra proferida no $8^{\circ}$ ENEPEA - Encontro Nacional de Ensino de Paisagismo em Escolas de Arquitetura e Urbanismo no Brasil, 2006, São Paulo: Setembro, 2006.

QUEIROGA, Eugenio Fernandes. Dimensões públicas do espaço contemporâneo: resistências e transformações de territórios, paisagens e lugares urbanos brasileiros. 2012. 284 f. Tese (Livre-docência) - Faculdade de Arquitetura e Urbanismo da Universidade de São Paulo, São Paulo, 2012.

SANTOS, Milton. A natureza do espaço: técnica e tempo, razão e emoção. São Paulo: Universidade de São Paulo, 2006. 384 p.

SHUTES, R. B. E. Artificial wetlands and water quality improvement. Environment International, v. 26, 2001, p. $441-447$

SPIRN, Anne Whiston. O jardim de granito: a natureza no desenho da cidade. São Paulo: Edusp, 1995. 345 p.

UNITED STATES ENVIRONMENTAL PROTECTION AGENCY - EPA. Constructed treatment wetlands. Office of Water, ago. 2004. Disponível em: <http://www.epa.gov/owow/wetlands/pdf/ConstructedW.pdf>. Acesso em: 29 mai. 2014.

UNIVERSITY OF ARKANSAS COMMUNITY DESIGN CENTER - UACDC. Low Impact Development - a design manual for urban areas. Arkansas: University of Arkansas Press, 2010. 227 p. 